\title{
Study of Operational Conditions in Octanizer and Hydro- Treating Units in Oil Refinery Company
}

\author{
Amir Samimi ${ }^{\text {a }}$, Soroush Zarinabadi ${ }^{\text {b,*, }}$, Amir Hossein Shahbazi Kootenaei ${ }^{\text {a }}$, Alireza Azimi ${ }^{\text {a }}$, \\ Masoumeh Mirzaei ${ }^{a}$ \\ ${ }^{a}$ Department of Chemical Engineering, Mahshahr Branch, Islamic Azad University, Mahshahr \\ ${ }^{\mathrm{b}}$ Department of Engineering, Ahvaz Branch, Islamic Azad University, Ahvaz, Iran
}

\section{Receive Date: 11 Jun 2019, Revise Date: 24 June 2019, Accept Date: 2 July 2019}

\begin{abstract}
The catalytic conversion of naphtha is a refinery process in which heavy naphtha feeds through the catalytic bed of several reactors at high temperatures and pressures that potentially increase the aromatics content of naphtha and its octane number. Usually, naphtha feed is used to remove the impurities that prevent useful reactions and cause poisoning of reformer catalysts. Operating abutments for the catalytic converter unit are temperature, pressure, metallurgical agent, hydrogen to hydrocarbon ratio, and chlorine ratio. In this study, Operational Conditions in Octanizer and Hydro-treating Units in oil refinery companies is investigated and optimized the conditions of catalysis.
\end{abstract}

DOI: $10.33945 / \mathrm{SAMI} / \mathrm{JCR} .2019 .3 .2$

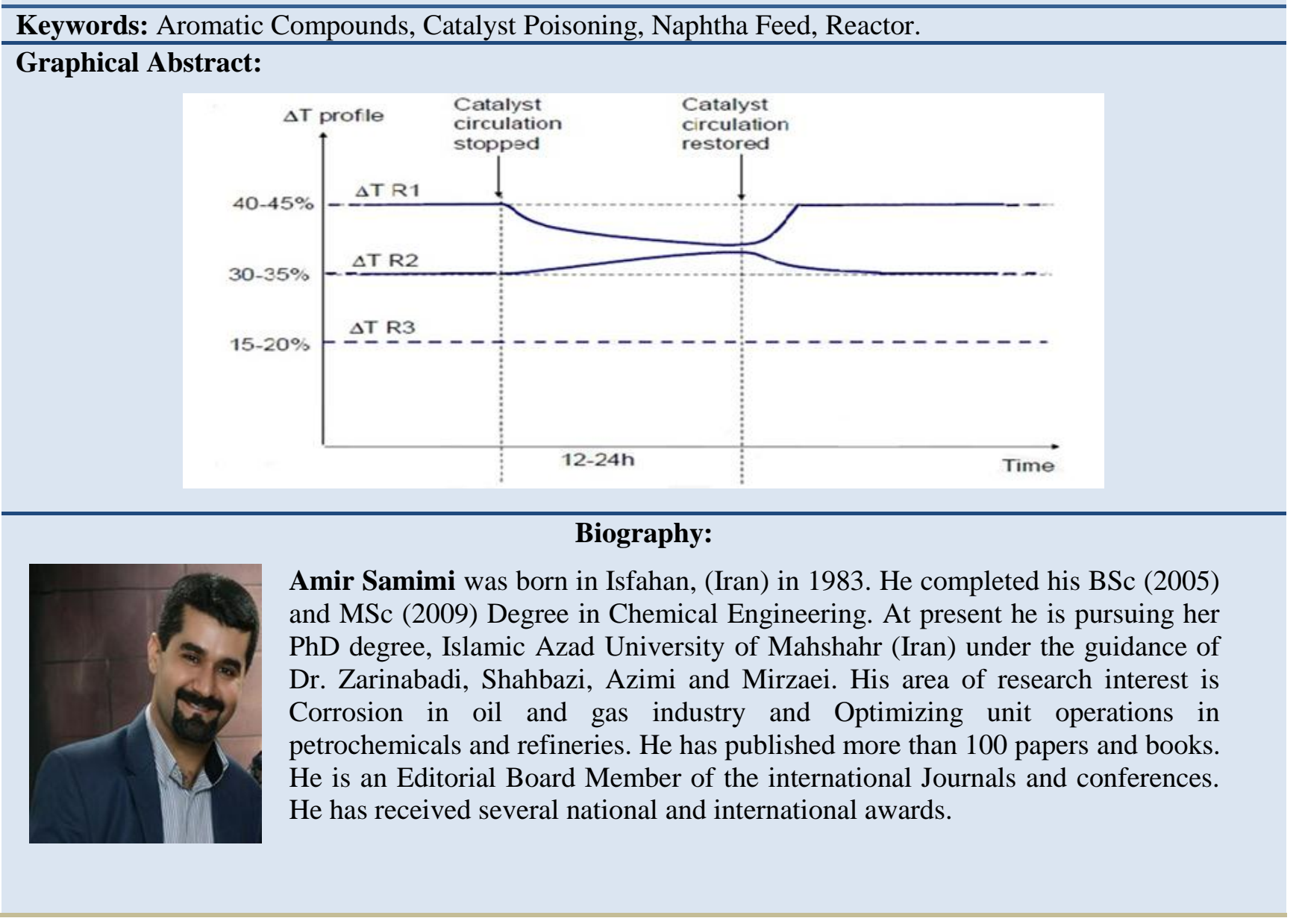




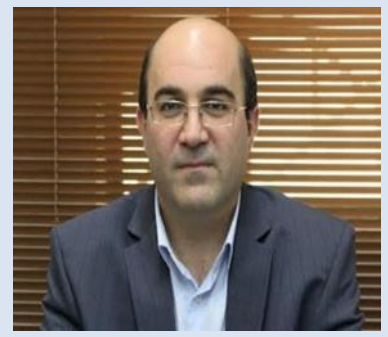

Soroush Zarinabadi was born in Mahshahr, Khuzestan, (Iran). He completed his BSc, MSc and Ph.D. Degree in Chemical Engineering. He currently works as an Assistant professor in Chemical Engineering at the Islamic Azad University of Ahvaz. His studies focused on Supercritical fluids. He has published more than 60 papers

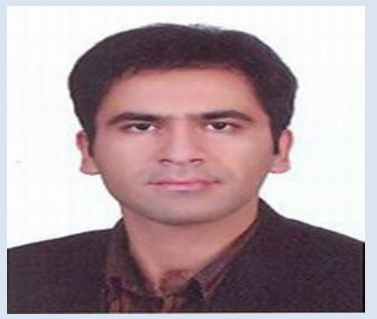

Amir Hossein Shahbazi Kootenaei was born in Ghaemshahr, (Iran). He completed his BSc, MSc and Ph.D. Degree in Chemical Engineering. He currently works as an Assistant professor in Chemical Engineering at the Islamic Azad University of Mahshahr. His studies focused on Catalyst. He has published more than 35 papers

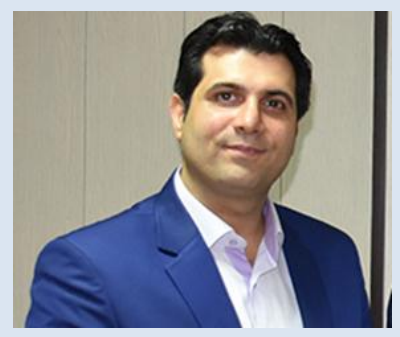

Alireza Azimi: He completed his BSc, MSc and Ph.D. Degree from in Chemical Engineering. He currently works as an Assistant professor in Chemical Engineering at the Islamic Azad University of Mahshahr. His studies focused on Reactors. He has published more than 80 papers

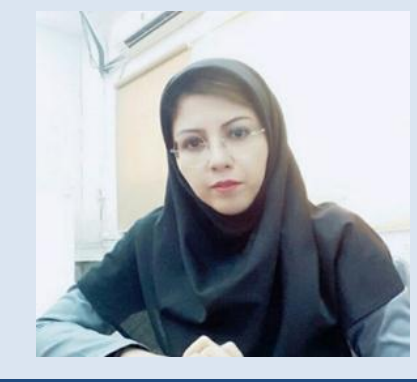

Masoumeh Mirzaei was born in Kermanshah, (Iran) in 1982. She completed her BSc (2004) and MSc (2006) and Ph.D. (2011) Degree in Chemical Engineering. She currently works as an Assistant professor in Chemical Engineering at the Islamic Azad University of Mahshahr. She studies focused on Thermodynamics. She has published more than 40 papers

\section{Introduction}

The dependence of advanced countries on petroleum products, especially gasoline and the outbreak of petroleum crises in the 1970s due to the increased consumption and extraordinary rise in petroleum prices and its products, urged industrialized countries to deal with energy problem and take a different approach. Undoubtedly, importance of the strategic product, gasoline in terms of current conditions, quality and quantity dimensions is not covered. The growth of imports and further dependence and the spread of environmental pollution and the prevalence of various diseases caused by pollution and the low quality of existence gasoline. One of the most important properties and quality features of a high quality gasoline product is the low level of pollutants such as sulfur, benzene, aromatic compounds, lead and manganese [1]. The higher the octane number is, the fuel is more resistant to combustion, pressure, and heat. The octane number is a measure to indicate the gasoline resistance to the heat, push and start of spontaneous combustion (no spark). The octane number is a fully conventional quantity of terms that have assumed the normal octane number of heptane, zero and the iso-octane 95, and the rest of the compounds have been calculated to these two. In the case of hydrocarbons, they are paraffinic the higher the number of branches increases, the higher the octane number increases (Figure 4). Being cyclic also increases the octane number. Regarding the mentioned cases, it is obvious that the conversion of normal paraffin hydrocarbons to iso paraffin's, naphthenes and aromatics leads to an increase in the octane number. The ignition of gasoline in the engine must be so that it does not strike or beat slowly. The engine will be beat when the fuel and air mixture, which is a high-ignition material due to congestion, will be affected sooner than the spark. Because before the piston reaches its highest point in the middle of the road and with an opposing force it goes down, it can 
cause serious damage to the parts of the engine. After another aspect, it can be said that the ability to compress the fuel before spontaneous combustion is the octane number, and the numerical scale is an agreement showing the burn of a fuel. The importance of the octane rating parameter of gasoline is that one way to increase the output power of the car's engine is to increase their concentration ratio, but this is achieved only by increasing the strength of gasoline resistance to spontaneous combustion, which is the same concept of the octane number. The fast burning petrol has caused a shock to reduce the efficiency and output power of the engine and can cause serious physical damage to parts of the engine.

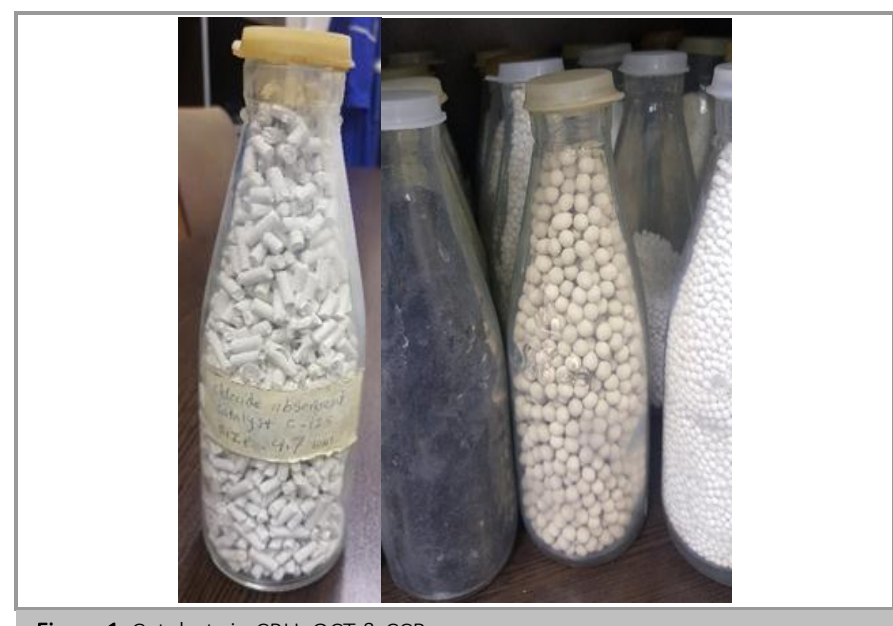

Figure 1. Catalysts in CRU, OCT \& CCR

\section{Duty of Process Octanizer Unit (OCT Unit)}

The duty of the unit is to produce reformate with high octane with high purity hydrogen. The Octanizing Reaction Section includes the following sections:

\section{Reaction Section}

Purification

Stabilizer

The purpose of the process is to produce:

A high octane reformate,

A hydrogen rich gas for use in PSA, PRIME $\mathrm{G}+$, NHT, ISOM and regeneration units,

A LPG cut sent to storage prior to treatment in RFCC Gas Recovery Section.

The design, operation, and control strategies of the unit are such as to maximize the production of the valuable high octane reformate stream and to ensure consistent quality of the rich hydrogen gas as this may affect the performance of the upstream and downstream hydrogen user. This process utilizes "state of the art" moving catalyst bed technology. The hydro treated naphtha feed stream is treated at very low pressure in three adiabatic reactors over a moving bimetallic catalyst bed in a hydrogen environment. Catalyst is withdrawn at a fixed rate from the reaction section and is regenerated in the Catalyst Regeneration Loop before returning to the reaction section. This continuous regeneration of the catalyst allows the catalyst beds to operate with a low coke deposit, thereby ensuring maximum catalyst performance at the selected operating conditions [2].

Pressure: Theoretically, the lower the pressure, the higher the reformate yield and hydrogen purity. (For a given space velocity - and feed characteristics.)

The pressure at the last reactor inlet is generally considered as the most representative for the purpose of this discussion. However, there is little flexibility since the unit and the recycle compressor are designed for a given pressure. Lowering the operating pressure below the design pressure results in higher pressure drop and is limited by the recycle compressor design power. The low pressure which favors high yields, favors also coke build up. During transient conditions (startup, shutdown, upsets) it is recommended to increase the pressure. Provision for this purpose is included in the design pressure of the equipment.

Space Velocity: Space velocity has been defined as "Process variables, Space velocity". It is the amount of liquid (expressed in weight or in volume), which is processed per hour and divided by the amount of catalyst (in weight or in volume). The inverse of the space velocity is linked to the residence time (or contact time) in the reactors. Knowing the liquid flow rate (or the space velocity), plus the recycle flow and the reactors operating conditions enables to calculate the actual flow in the reactor, hence the contact time. The lower the space velocity (i.e. the higher the contact time), the higher the severity, assuming all other conditions unchanged. Lowering the space velocity has, then, the same effects as increasing the temperature i.e., it:

- Increases the octane.

- Decreases the product yields.

- Decreases $\mathrm{H}_{2}$ purity.

- Increases coke deposit.

If temperature increase is limited lowering space velocity can give an additional boost to octane. Operators must bear in mind that each time liquid feed rate is changed, a temperature correction must be applied if octane is to be maintained. When feed is increased, temperature must be raised and conversely, when feed is reduced, temperature must be lowered.

Distillation Range: One feed property that the Unit Owner can control is the distillation range. The naphtha end point is controlled in the upstream unit 
distillation (crude unit fractionator for straight run naphtha). The initial boiling point is controlled at the naphtha hydrotreater splitter. This IBP enables to include in the feed components such as methyl cyclopentane (IBP $72{ }^{\circ} \mathrm{C}$ ) and cyclohexane (IBP 80 $\left.{ }^{\circ} \mathrm{C}\right)$ which are benzene precursors. In some cases, however, the benzene content in the gasoline is strictly limited. In these cases, the IBP must be raised to $82{ }^{\circ} \mathrm{C}$ or above. A feed with a low IBP generally contains more $\mathrm{C} 6$ and lighter paraffin's and requires a higher severity to obtain the same octane number than a feed with a higher IBP. One must also consider the distillation final boiling point (FBP). High FBP means heavier fractions which are richer in aromatics and naphthenes and thus are easier to process. However the high boiling point fractions are potential sources of polynuclear aromatics which are coke precursors. FBP higher than $180{ }^{\circ} \mathrm{C}$ are generally not recommended.

Naphtha: The naphtha feed to this unit is the hydro treated heavy naphtha coming from the splitter of the Hydro treatment unit. The feed composition and properties are given hereafter. The Octanizing catalyst is a high purity alumina based catalyst, impregnated with platinum and promoters. It is highly sensitive to impurities in the feedstock. The following Figure 4 lists the maximum allowable limits of impurities in the feed. It is of utmost importance that the performance of the Hydro treating unit is such that the impurities levels of the Octanizer feed do not exceed these levels. Discussions regarding feed poisons and their effects will be discussed further in this design book and will be covered in detail in the operating instructions manual provided at a later date [3].

Products Specification: There are essentially three primary products from the Octanizer unit:

A Reformate stream,

A hydrogen rich gas stream,

A LPG stream.

There is one additional secondary purge gas stream routed to fuel gas header:

Fuel gas from LPG absorber drum, which is routed to the Fuel Gas network.

Expected characteristics are described in the following pages.

Reformate: This product comes from the stabilizer bottom and is sent to a storage tank.

LPG to Storage: This product comes from the stabilizer reflux drum

$\mathrm{H}_{2}$ Rich Gas: This gas is the hydrogen production purified in the re contacting drum. The high purity hydrogen gas is routed through chloride absorbers to remove all traces of chloride. The clean gas is used in:

Isomerization Unit (ISOM),

PSA Unit,

Naphtha Hydro treated Unit

Prime G+ Unit,

Octanizer Regenerative Loop

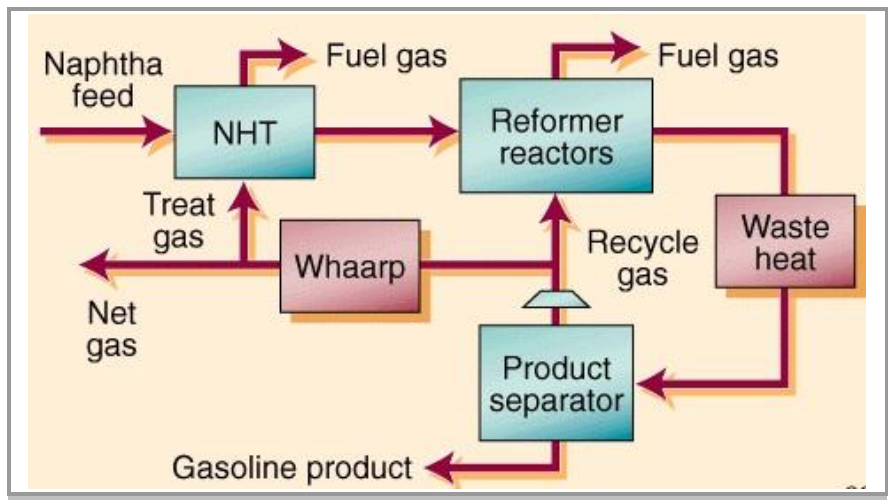

Figure 2. Schematic of feed for OCT Unit

\section{Fuel Gas from LPG Absorber Drum}

This product is purged from the LPG absorber drum. Composition and rates for the two operating cases are given hereafter:

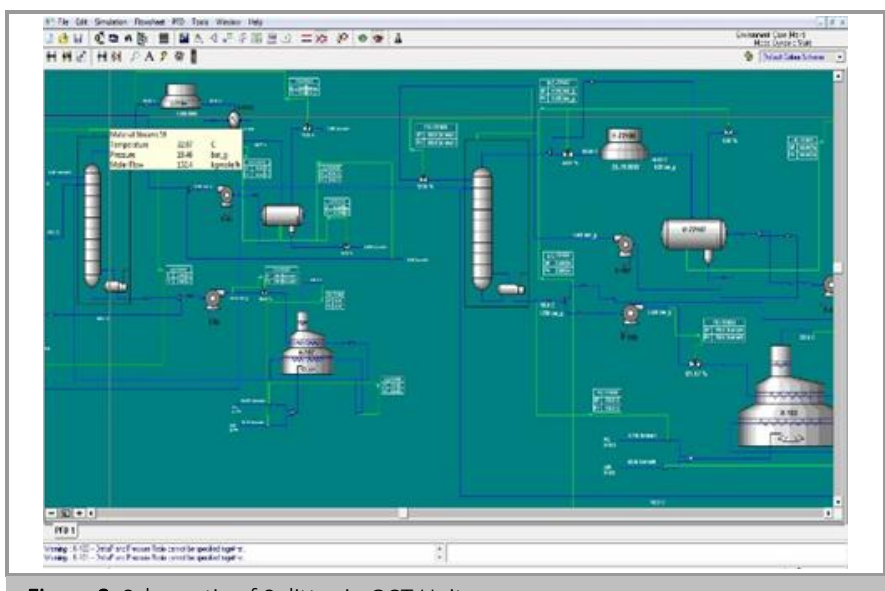

Figure 3. Schematic of Splitter in OCT Unit

The reforming reactions take place in moving bed catalytic reactors from which the catalyst is withdrawn, then regenerated and recycled. The catalyst circulation and regeneration are performed on a continuous basis with full automatic control of all the operations. A high temperature (in the range of $500^{\circ} \mathrm{C}$ ) is required to promote the chemical reactions which improve octane number. Therefore, the need for a preheating of the feed. Moreover, some of the desirable reactions are highly endothermic. This leads to split the bulk of the catalyst into several reactors with intermediate re-heaters. The high performance of the Octanizing process is largely owed to low pressure 
operation coupled with high temperatures; which, in conventional fixed bed reactors would lead to very short cycle length. Hence Octanizing involves a continuous catalyst regeneration. Continuous regeneration eliminates the need of shutdown for regeneration of the earlier fixed bed reformers. It also minimizes the amount of catalyst in the unit, while allowing high reformates yield and quality [4].

\section{Reaction Section}

Feed to the Catalytic Reforming unit is a hydro treated heavy naphtha from the bottom of the naphtha splitter. The mixture enters the reforming unit battery unit directly from the naphtha splitter bottoms pumps. A chloriding agent and water are injected as the feed enters the unit to control the water-chloride equilibrium (if the continuous regenerator is out of service) for optimum reforming catalyst performance. Also, a sulfiding agent is added at the feed inlet to the unit. The small quantity of the sulfiding agent prevents the coke deposit in heater. After entering the unit and the chemicals injection, the feed is passed through filters to remove any particulate matter which may deposit in the welded plate exchanger. The feed is then mixed with the recycle hydrogen from the recycle compressor in the welded plate's heat exchanger. This is a true counter-current exchanger designed for minimum pressure drop and maximum heat recovery against reactor effluent. The combined feed and recycle hydrogen are preheated here against the third reactor effluent and then are further heated to the required first reactor inlet temperature in preheater. The reactors are radial flow types, the feed flowing through the catalyst bed from the outer circumference towards the center pipe. In the first reactor, the reactions are predominantly endothermic and therefore the reactor effluent requires reheating in the first inter-heater to the required inlet temperature of the second reactor. The reactions in this reactor are less endothermic but still require reheating in before entering the third reactor. The effluent leaves the third reactor at approximately $451-473{ }^{\circ} \mathrm{C}$ (depending on the position in the cycle and feed) and $3.5 \mathrm{barg}$. The inlet temperatures of the three reactors are identical. In the regeneration unit, the catalyst is regenerated by a means of an automatic regeneration loop system. Catalyst circulation is achieved either by gravity flow or by gas lift systems. A detailed description of the regeneration unit is provided in the corresponding process book [5]. The three reactors temperatures are controlled by regulating fuel gas flow rate to the burners. Leaving the third reactor, the effluent after heat exchange against reactor feed is cooled by air and water exchangers respectively before entering the separator drum. A portion of the separated gas is compressed in a steam turbine driven recycle gas compressor and is recycled to the reactors. The remaining gas which constitutes the hydrogen production gas is routed to a compression and recontacting section to improve hydrogen purity and liquid hydrocarbons yield. The separated liquid is pumped under level control to be recombined with the $\mathrm{H} 2$ rich gas in the re-contacting section. The pressure of the reaction section is controlled by varying the booster compressors spillback and the purge gas flow rate of the separator drum. The purge gas is routed to flare and, under ideal conditions, its flow rate is zero [5].

\section{Compression and Re-Contacting Section}

The hydrogen production gas is mixed with the hydrogen gas stream from the Continuous Catalyst Regeneration section and routed to the booster compressor after passing through the K.O drum. Booster compressor provides a three-stage compression of the $\mathrm{H} 2$ production gas from 2.6 barg to $27.5 \mathrm{barg}$. A first inter-stage cooler and a first interstage drum, are required between the first two stages to cool the compressed stream and remove the condensed hydrocarbons. The condensed liquid is sent back under level control to upstream of the reactor effluent trim cooler. The vapor from the inter-stage K.O. drum is then compressed in the second stage of the booster compressor. A second inter-stage cooler and a second inter-stage drum, are required between the second and third stages to cool the compressed stream and remove the condensed hydrocarbons. The condensed liquid is sent back under level control to upstream of the reactor effluent trim cooler. The vapor from the inter-stage K.O.drum is then compressed in the third stage of the booster compressor. The third stage discharge flow is combined with the liquid hydrocarbons from the separator re-contacting pumps. The re-contacted mixture is then cooled against water in the re-contacting trim cooler before entering the recontacting drum [6]. The target temperature is $38{ }^{\circ} \mathrm{C}$ at $37 \mathrm{barg}$ in the re-contacting drum. These conditions of the final stage separator for the hydrogen production gas are designed to maximize the concentration of hydrogen in the hydrogen rich gas product. The gas is then treated to remove chlorides in the hydrogen rich gas chloride absorbers operated in series, before distribution to the users:

\section{Regeneration Loop, \\ Hydro-Treatment Unit, \\ Prime G+ Unit, \\ PSA Unit,}

Isomerization Units. 
The separated liquid from the re-contacting drum is sent under flow control with level reset to the LPG recovery and stabilization section.

\section{LPG Recovery and Stabilization Section}

The separated liquid is contacted with stabilizer offgas and allowed to separate in the LPG Absorber Drum. The purpose of this step is to recover the maximum quantity of LPG, i.e. C3 and C4's from the stabilizer overhead. Vapor is sent to fuel gas. This stream is predominantly light ends. Separated liquid is pumped by LPG Absorber Bottom Pumps, under flow control with level reset and is sent through the stabilizer feed/bottom exchanger to the Stabilizer Feed Chloride Adsorbers (in order to remove all traces of chlorides) and finally through the stabilizer feed/bottom exchanger to enter the stabilizer column.

Note that a back pressure is maintained on the stabilizer feed chloride adsorbers to ensure no vaporization occurs with the stabilizer feed. The target operating temperature for chloride removal is approximately $100{ }^{\circ} \mathrm{C}$. The stabilizer operating at 15.5 barg at the top allows reducing the $\mathrm{C} 4$ fraction in reformate to less than $1.0 \mathrm{vol} \%$ and the $\mathrm{C}+$ fraction in the LPG to less than $0.5 \%$ wt. The stabilizer is reboiled with a fired Reboiler, circulating with Stabilizer Reboiler Pumps. Temperature control is on trays. Stabilizer overhead is partially condensed in Stabilizer Air Condenser and in Stabilizer Trim Condenser, to collect in Stabilizer Reflux Drum. The reflux drum overhead vapor is routed back to for LPG recovery. A part of the separated liquid is pumped by Stabilizer Reflux Pumps, under flow control with temperature reset back to as reflux. The remaining part of the separated liquid is routed to the battery limits. Reformate from the bottom of the stabilizer is cooled in the Stabilizer Feed/Bottom Exchangers, and further cooled down in Reformate Air Cooler and Reformate Trim Cooler before being sent to storage.

\section{Octanizing Catalyst}

For continuous regeneration technology, the main features of the catalyst are:

High purity alumina support having a high resistance to attrition,

High stability and selectivity due to platinum associated with other metal promoters,

High regenerability, ideal for a continuous regenerating operation.

Catalyst Activity: As previously mentioned here are two basic functions of the reforming catalyst, a metallic function and an acidic function. A correct equilibrium between the two functions ensures maximum activity, selectivity and stability. It is important that the equilibrium be maintained throughout the life of the catalyst [7].
Metallic Function: Platinum is the chosen metal for the reforming catalyst along with other promoter's. This function catalysis the dehydrogenation and dehydrocyclization reactions.

Acidic Function: This is provided by the chloride and water adjustment on the alumina support. To maintain the acidity of the catalyst at the correct level a balance must be made between the moisture in the recycle gas and the chloride on the catalyst. This system provides a means for precise control of this catalyst acidity level while the plant is in operation.

Naphtha catalyst conversion unit with a continuous resuscitation has been designed the refinery's Octanizer commercial name aimed at increasing the gasoline octane number. But it will not be possible to reach the ideal conditions and specifications of reformat gasoline product due to forced changes in unit capacity, combination of feed percentage and changing the conditions of upstream units and process conditions and fluctuations of control parameters and different operational conditions and problems of side services units and utility, etc. Without finding practical solutions and optimizing processes, it will not be possible. In this regard, the following parameters should be considered:

Impact of Partial Hydrogen Pressure: Hydrogen dehydration rate has been chosen as a basis at 95 (because the logarithm 95 is equal 2). The rate of other reactions has been measured based on this. At a partial pressure of hydrogen 10 bar, Naphthenes hydrogen dehydration is approximately 10 times faster than the isomerization and 30 times faster than ringing and about 50 to 60 times faster than the cracking (hydrogen breaking). At the appropriate high pressure, the amount of coke compared to other reactions is small, but in low pressures it increases significantly when the catalyst conversion unit occurs. Overall, the operation at low pressure is more convenient. The cracking rate is decreased and the cyclic rate will be increased similar to the amount of coke formation. On the other hand, the basis of thermodynamic laws is more advanced in the low pressure of dehydrogenation and cyclic reactions. The only low pressure weakness is the high amount of coke formation, which is offset by a continuous recovery operation of the catalyst.

The Impact of Temperature: The effect of temperature on different reactions and activation energy is associated with the slope of the graph.

The dehydrogenation reaction has a balanced activation energy $(20 \mathrm{kcal} / \mathrm{mol})$ like isomerization reaction $(25 \mathrm{kcal} / \mathrm{mol})$ and thus temperature only increases the amount of these reactions. Cyclic reaction has the higher actuation energy $(30 \mathrm{kcal} / \mathrm{mol})$ and then, temperature increases the rate of this 
reaction. Cracking and coke formation reactions have higher actuation energy ( 35 and $45 \mathrm{kcal} / \mathrm{mol})$. The rate of these undesirable reactions is significant with increasing temperature.

The Impact of Carbon Numbers: kinematic studies of chemical reactions have been more complex due to the presence of molecules with the different number of carbon atoms. As for thermodynamic equilibrium, it indicates that the amount of reactions is a function of the length of the molecular chain of the raw material. In general, the ratio of the cracking reactions increases with increasing the number of carbon atoms, as the cyclic reaction rate is accompanied by a sudden increase between hexane and heptane, as between heptane and octane. Overall, carbonization of paraffin C6 to benzene is harder than converting paraffin $\mathrm{C} 7$ to toluene which is harder than converting paraffin $\mathrm{C} 8$ to xylene so the most appropriate cutting in catalyst convertor unit feed is cutting C7-C10.

The Impact of Hydrogen to Hydrocarbon Ratio: High hydrogen pressure is required to prevent coke formation. Pressure is maintained by returning part of the output hydrogen. There are also some $\mathrm{C} 1$ to $\mathrm{C} 5$ hydrocarbons in the return gas. It is purer at the start of the hydrogen operation. The molar ratio of hydrogen to hydrocarbon changes from 5 to 10 . Typically, lower ratios are preferred, however, to the extent that the formation of coke does not increase. The effect of the hydrogen to hydrocarbon ratio is similar to the effect of total pressure. The effect of this molar ratio on dehydrogenation reactions and paraffin's cyclic with dehydrogenation is relatively reduced mentioned reactions [8].

Catalyst Distribution in Reactors: The thermodynamic and kinetics study of the reactions showed that the best operating temperature range in order to speed the desired reactions and limit adverse reactions is approximately between 450 and $520{ }^{\circ} \mathrm{C}$ at an acceptable level. For the special case, the most appropriate operating temperature is selected based on the quality of the feed (the distillation range, PNA, and...) and the quality of the product required. Due to the intense warming up of desired and critical reactions (including Naphthenes dehydrogenation reactions and paraffin cyclic with dehydrogenation), the optimal temperature cannot cover all the volume of the catalyst. In addition to, dehydrogenation is the fastest reaction, in other words, the drop in temperature is very rapid for the first part of the catalyst. In order to preserve the catalyst activity, once the temperature reaches a certain level (which depends on the present reactions), the reactor feed becomes more heated. For this purpose, the catalyst is distributed in several reactors (3 or 4$)$ and intermediate heaters are predicted. Therefore, there is no need to have more than $10 \%$ of the catalyst in the first reactor, since dehydrogenation is performed at a very low temperature and does not require longer reaction. Heating the output reactor current allows naphthenes hydrogenation to be carried out and paraffin cyclic reactions with dehydrogenation starts. More than $15 \%$ of the next catalyst is distributed in the second reactor. For temperature degradation the flow must be heated again in order to continue paraffin cyclic reaction with dehydrogenation [11]. The catalyst distribution for this one, which is basically the same unit, is:

First reactor: $20 \%$ Catalyst

Second reactor: $30 \%$ Catalyst

Third reactor: $50 \%$ Catalyst

Obviously, any particular case has its own catalyst distribution. Basically, the operational guide of the main reactions is as follows:

First Reactor: dehydrogenation, isomerization

Second Reactor: dehydrogenation, isomerization, hydrocracking, paraffin cycling with dehydrogenation

Third Reactor: hydrocracking, paraffin cycling with dehydrogenation.

From the above analysis it can be concluded:

$\square$ Dehydrogenation reactions are very fast, about one order of magnitude faster than the other reactions.

$\square$ Low pressure favors all desirable reactions and reduces cracking. To compensate the detrimental effect of low pressure on coking, low pressure reformer requires continuous catalyst regeneration.

$\checkmark$ An increase in temperature favors the kinetics of dehydrogenation, isomerization, Dehydrocyclization, but accelerates the degradation reactions (cracking, coking) even more. Consequently an increase in temperature leads to an increased octane associated with a decrease in reformate yield.

The reaction rates of such important reactions as paraffin's Dehydrocyclization increase noticeably with the number of carbon atoms. Cyclization is faster for $\mathrm{C} 8$ paraffin than for $\mathrm{C} 7$, and for $\mathrm{C} 7$ than for C6. Consequently the $\mathrm{C} 7-\mathrm{C} 10$ fraction is the most suitable feed [9].

\section{Catalyst Activity, Selectivity, Stability}

The main characteristics of a catalyst other than its physical and mechanical properties are:

The Activity: which expresses the catalyst ability to increase the rate of the reactions involved. It is measured by the temperature at which the catalyst must be operated to produce reformate of a given octane number, for a given feed and given operating conditions. 
The Selectivity: expresses the catalyst ability to favor desirable reactions rather than others. It is practically measured by the $\mathrm{C} 5+$ reformate and hydrogen yields, for a given feed and octane number, and given operating conditions.

The Stability: characterizes the change with time of the catalyst performance (i.e. activity, selectivity) when operating conditions and feed are stable. It is chiefly the coke deposit which affects stability, through its inhibition of the catalyst acidity and decrease of metal contact area. Traces of metal in the feed also affect stability adversely. Stability is generally measured by the amount of feed treated per unit weight of catalyst (i.e. M3 of feed per $\mathrm{kg}$ of catalyst). $\mathrm{C} 5+\mathrm{wt}$ reformate yield at steady conditions is also an indirect measure of the stability.

\section{Octanizing Catalyst Characteristics}

The catalysts are a multi-metallic catalyst consisting of platinum plus metal promoters on an alumina support.

The main features:

High purity alumina support having a strong resistance to attrition.

High stability and selectivity due to the platinum associated with other metals (promoters).

High regenerability ideally suited for the continuous regeneration operations.

High chloride retention.

The association of the above mentioned qualities with the continuous regeneration gives the following advantages:

High reformate yield.

High hydrogen yield

High stream factor

Low life duration

Low catalyst inventory

Low operating cost

The detailed Octanizing ${ }^{\circledR}$ CATALYSTS chemical and physical properties are listed in chapter "Catalyst properties and special procedures".

\section{Catalyst Mechanism}

Metallic and Acidic Functions: The catalyst affects reaction rates through its two different functions: metallic and acidic, which promote different type of reactions. Dehydrogenation and hydrogenation reactions are enhanced by the catalyst metal. Structural rearrangements of the molecules (from linear to cyclic for instance) which involve a reorganization of the carbon bonds are primarily catalyzed by the acidic function of the support. Because of its high activity in hydrogenation and Dehydrocyclization, platinum has been selected for the base catalytic metal. Promoters have been added to improve catalyst selectivity and stability. The support is high purity alumina (acidic function) which is chiefly active for the cyclization of the paraffin's to aromatics. In short, the main reactions involved in reforming processes are catalyzed essentially either by the support or the metal functions, as indicated below:

\section{Dehydrogenation}

\subsection{Metallic function Dehydrocyclization}

Metallic + acidic functions Isomerization

Acidic function Hydrogenolosis

Metallic function Hydrocracking

Metallic + Acidic Functions

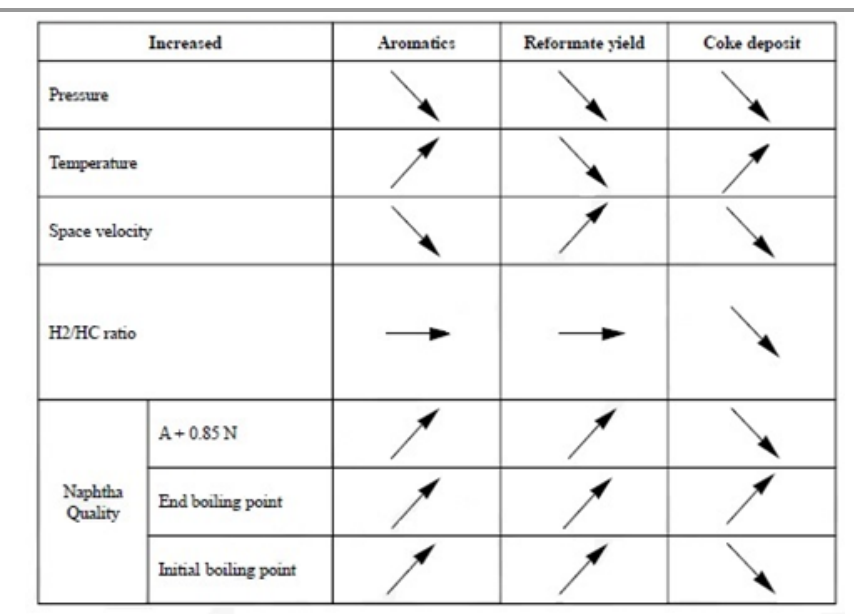

Figure 4. Catalyst Activity

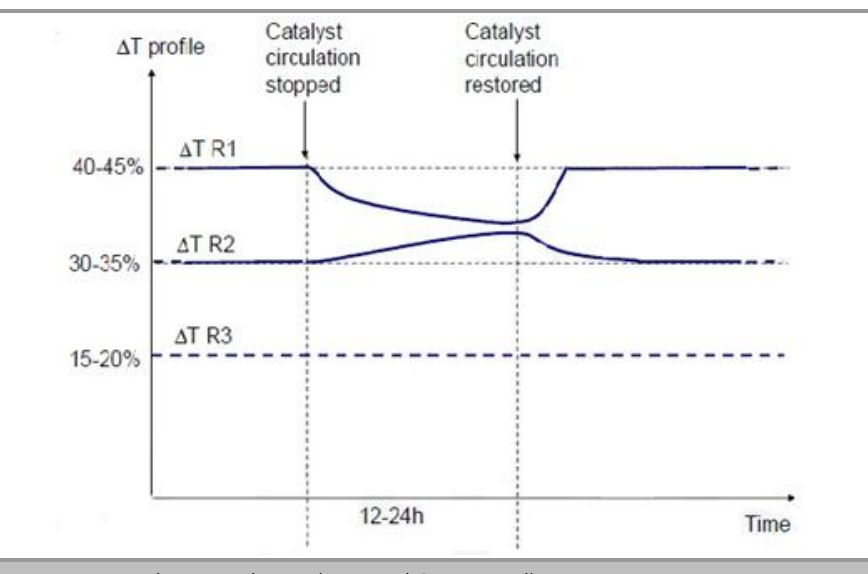

Figure 5. Catalyst Circulation (Stopped \& restored)

\subsection{Metallic Function}

For a maximum catalyst activity, the metal should be highly dispersed on the alumina support and under the minimum possible particle size (actual figure is in the range of 1.10-6 $\mathrm{mm}$ ). This high dispersion and micrometric particle size, which result from the special manufacturing process, must be maintained during the catalyst life by the use of proper operating conditions. A decrease of the performance of the metallic function can be caused by: 
A poisoning of the metallic phase (see chapter 3.5.8 "Catalyst contaminants" of operating instruction for details), or an alteration of the metallic phase on the support.

Indeed, a sintering of the metallic phase may occur during the first regeneration step (coke burning), due to local high temperatures and high level of partial pressure of water. The oxy-chlorination step, which is led right after coke burning, allows a good redispersion of this metallic phase. A wet reduction leads also to sintering of the metallic phase.

Acidic Function: A certain level of acidity of the catalyst support is required to promote some of the desired reactions (isomerization, Dehydrocyclization) which consequently lead to a maximization of the desired performance (reformate production, hydrogen or octane number yields). The optimum level of acidity changes somewhat with these desired performance.

The acidity of the catalyst is dependent on the amount of chlorine which is fixed on the catalyst at the manufacturing stage. In operation, the chlorine content of the catalyst varies with the recycle gas moisture and the elution of chlorine by water, which happens mainly during the coke burning step, due to the formation of combustion water. That's why this level must be adjusted during oxy-chlorination and maintained in the optimum range of $0.9 \%$ to $1.1 \% \mathrm{wt}$. The simplified theory, generally accepted today, is that the optimum acidity level (which varies with the requested performance) is a function of ratio of the $\mathrm{OH}$ - bonds to the CL- bonds, which are adsorbed at the catalyst surface. This ratio, in turn, is a function of the water and HCL content in the recycle gas, because of the equilibrium which exists between water and $\mathrm{HCL}$ in the recycle and $\mathrm{OH}-$ and $\mathrm{CL}$ - bonds on the catalyst.

Excess of Moisture: Good acidity of the catalyst is controlled by the balance between $\mathrm{H}_{2} \mathrm{O}$ and HCL. An excess of water in the recycle will shift the balance towards excess of $\mathrm{OH}$ - and thus reduce the activity [10].

Lack of Moisture: Conversely, if the amount of water in the recycle is too low (an infrequent case) the catalyst is reputed too dry, the OH- to CL- balance is shifted towards CL-. In other words, the catalyst is over-chlorinated, which means its acidic function is exacerbated (trend to hydrocracking). Of course, overchlorination of the catalyst may result merely from the accidental presence of chlorine, or uncontrolled addition, in the feed. There are a couple of other occurrences worth mentioning:

- If a catalyst is excessively dry (i.e. it has been operated with a deficiency of water for some time) it will exhibit a very high acidic function indicated by in an increased hydrocracking activity.

- If a catalyst (especially in case of excessively dry catalyst) undergoes a water upset (amount of water in the recycle over $50 \mathrm{ppm}$ vol.) a situation may occur where the water displaces the chlorine from the first reactors towards the last reactor with a subsequent temporary increase of the acidic function and hydrocracking activity in the last reactor.

To conclude, for an optimum operation of the Octanizing Unit:

- The water content in the recycle must be maintained between 15 to $25 \mathrm{ppm}$ volume and the associated HCL content should be approximately $1 \mathrm{ppm}$ volume.

- Note that the determination of the HCL content is not very reliable.

- The chlorine content of the regenerated catalyst must be maintained between 0.9 to $1.1 \%$ wt. The chlorine injection rate in the oxy-chlorination zone of the regenerator, based on catalyst analysis.

- Alteration of Catalyst Activity: The causes and consequences of catalyst activity loss (due to an unbalance of either the acidic or metallic function) are listed Remedial actions are covered in 3.5.8 (Catalyst contaminants).

Catalyst Contaminants: Catalyst contaminants are classified in two categories. Temporary poisons (also called sometimes inhibitors) and permanent poisons.

Temporary Poisons: are those which can be removed from the catalyst without a shutdown and for which the catalyst proper activity and selectivity is restored once the contaminant disappears. The effect of temporary poisons, if the operators maintains the operating conditions prevailing before the poisoning, is a temporary decrease of performance. The most common temporary poisons: (inhibitors) of reforming catalysts are sulfur, organic nitrogen, water and oxygenated organics, halogens. Coke, in a regenerative unit, although it could fall within this category is treated separately.

Permanents poisons are those which induce a loss of activity which cannot be recovered, even with a regeneration. For the conventional fixed bed catalysts and the continuously regenerated catalysts, the main permanent poisons are arsenic, lead, copper, iron, nickel, chromium, mercury, sodium, potassium. In order to ensure the optimum use of the catalyst, a proper design shall include:

- The removal of poisons from the feed prior to its introduction to the unit 
- The necessary procedures to remove, as far as possible, the temporary poisons from the contaminated catalyst.

Impurities from the feed are removed by pretreating units. However their efficiency is never complete, and generally limited depending upon the type of impurities to be removed. In addition, a poor adjustment of the operating conditions of the pretreating unit results in a decreased efficiency. A smooth and successful operation of this reforming unit requires the proper adjustment and control of the operating conditions of the pretreating unit.

\section{Temporary Poisons}

Sulfur: Sulfur is the most common impurity found in the feed of any reforming unit. The maximum allowable concentration is $0.5 \mathrm{ppm}$ wt expressed as $\mathrm{S}$. Whenever possible, operation at lower sulfur content will provide additional catalyst stability and selectivity [11].

Mechanism: Poisoning is caused by $\mathrm{H}_{2} \mathrm{~S}$, either contained in the unit feed, or resulting from the decomposition, on the catalyst, of sulfur compounds contained in the feed. $\mathrm{H}_{2} \mathrm{~S}$ reacts with platinum according to the equilibrium reaction:

$\mathrm{Pt}+\mathrm{H}_{2} \mathrm{~S} \quad \mathrm{PtS}+\mathrm{H}_{2}$

Consequently it reduces the activity of the catalyst while decreasing the metallic contact area. The same type of reaction occurs with $\mathrm{H}_{2} \mathrm{~S}$ towards the other catalyst promoters, and further reduces the catalyst activity.

Effect of Sulfur Contamination: Sulfur contamination inhibits the metal function of the catalyst. This is indicated by:

A decrease in hydrogen yields.

A decrease in recycle purity.

An increase in hydrocracking (LPG yield increase).

$\square$ A reduced temperature drop in the reactors especially first one and sometimes an increase of temperature drop across the second reactor.

An increase coking rate.

Prevention and Causes of Contamination: Sulfur removal is achieved by pretreating the naphtha feed, which results in $\mathrm{H}_{2} \mathrm{~S}$ production. Poor operation of the pre-treated is generally the cause of sulfur poisoning of the reforming catalyst:

- $\quad$ Either low activity of the hydrotreater catalyst.

- Sudden change of feed characteristics (EBP, total sulfur).

- Or too low hydrotreater hydrogen partial pressure or reactor temperature which leads to an insufficient sulfur removal. Unsatisfactory operation of the hydrotreater stripper can also result in dissolved $\mathrm{H}_{2} \mathrm{~S}$ being fed to the reforming unit. In such case water content of the reforming feed also increases. An additional protection to avoid $\mathrm{H}_{2} \mathrm{~S}$ upsets to the reforming unit is to provide a sulfur guard reactor on the feed.

Detection: Analytical methods are available to detect sulfur in the unit feed. A very easy way, however, is to check sulfur content in the recycle gas. The $\mathrm{H}_{2} \mathrm{~S}$ content in the recycle which corresponds to the 0.5 ppm wt in the feed, is approximately $1 \mathrm{ppm}$ (volume). $\mathrm{H}_{2} \mathrm{~S}$ detection can also be performed on the stabilizer column off-gas (about $5 \mathrm{ppm}$ volume in stabilizer column off-gas corresponding to $1 \mathrm{ppm}$ volume in the recycle gas).

Remedies: When the sulfur content in the recycle gas increases, the reactor inlet temperature must be reduced. Typically for an $\mathrm{H}_{2} \mathrm{~S}$ level of 5 vol. ppm in the recycle the reactor inlet temperature must be lowered to $480^{\circ} \mathrm{C}$; the reformer feed must be reduced accordingly to maintain product quality (octane number). These conditions must be maintained until the cause of the upset has been found and corrected. The high severity operating conditions can only be resumed when the $\mathrm{H}_{2} \mathrm{~S}$ content in the recycle gas is lower than $1 \mathrm{ppm}$ vol. In no instance shall the lost activity due to sulfur poisoning be compensated with temperature.

Nitrogen: Nitrogen is less frequently present in the reforming feed than sulfur. Scarcely present in straight run naphtha, nitrogen is a usual impurity of cracked naphtha and may also result from injection of amine based corrosion inhibitors. The maximum allowable concentration in feed is $0.5 \mathrm{wt}$ ppm expressed as organic nitrogen.

Mechanism: In fact, organic compounds containing nitrogen are responsible for inhibition but nitrogen gas itself $\left(\mathrm{N}_{2}\right)$ has no detrimental effect. Contamination is due to $\mathrm{NH}_{3}$ formed by decomposition of compounds containing organic nitrogen, on the catalyst. Then $\mathrm{NH}_{3}$ which is alkaline, reacts with chlorine decreasing the acidic function of the catalyst and producing ammonium chloride $\mathrm{NH}_{4} \mathrm{Cl}$. This compound is volatile in the conditions of the reactors and is eliminated inducing a loss of chlorine.

Effect of Nitrogen Contamination: Nitrogen contamination reduces the acidic function and is indicated by:

- A decrease in octane.

- A slightly increased in hydrogen production.

- A reduced reactor temperature drop.

On top of this, ammonium chloride present in the recycle gas can deposit in coolers, separators compressors etc. Creating mechanical problems, as it 
becomes solid under $80^{\circ} \mathrm{C}$. It is worth remembering that $0.5 \mathrm{ppm}$ wt of organic nitrogen in the feed.

Prevention and Causes of Contamination: Organic nitrogen removal is also achieved by naphtha pretreating of the feed. But it shall be emphasized that nitrogen removal is more difficult than sulfur. Efficient nitrogen removal often requires the use of a specific catalyst, also active for desulfurization, but generally operating at higher hydrogen partial pressure. Naphtha, with high nitrogen content must not be fed to a pretreated not designed for it. Cracked naphtha's are generally characterized by high organic nitrogen content, consequently cracked naphtha's shall never be introduced to a pretreated designed to process straight-run feeds without getting technical advice from the licensor and/or the catalyst manufacturer. In the pretreating unit, decomposition of nitrogen compounds gives $\mathrm{NH}_{3}$.

However the amount is generally limited and easy to remove by stripping. The corrosion inhibitor (amine based), usually injected in the pretreatment stripper overhead line shall be selected to be decomposed at the condition of the stripper to avoid contamination of the stripper bottom product (Reforming feed). In fact, the presence of nitrogen compounds in the feed is typically due to a low activity of the pretreatment catalyst towards de-nitrification.

Detection: There is no available method for ammonia detection in the recycle gas. Thus laboratory analysis needs to be performed on the feed to detect nitrogen compounds.

Remedies: When nitrogen contamination is detected operators must:

Not try to make up for the drop in octane number of reformate by an increase of the reactor inlet temperature. This will only increase the loss of chlorine.

Take the necessary actions to lower the nitrogen content down to the acceptable figure of $0.5 \mathrm{ppm}$ wt.

\section{Water and Oxygenated Organic Compounds}

Oxygenated organic compounds (methanol, MTBE, phenol...) are converted into water at reactor conditions. Water is not exactly a poison since some water is necessary to activate the acidic function of the catalyst. However, in usual practice, elimination of water from reforming feed is a major concern of operators, because an excess of water leads to a decrease in catalyst activity. Water is often present in naphtha feeds, moreover water is frequently injected in reforming feed hydrotreater to remove formed salts in the cold part of the reaction section. The maximum allowable content is $4 \mathrm{ppm}$ (wt) in the feed which corresponds to approximately $20 \mathrm{ppm}$ volume in the recycle gas for typical conditions $(\mathrm{P}=2.5-10 \mathrm{barg}$; $\mathrm{T}$ $=40^{\circ} \mathrm{C}$ at the separator).

Mechanism: Water affects the acidic function of the catalyst, as previously explained ("Catalyst mechanism") [12].

Prevention and Causes of Contamination: Water removal in usually achieved in the stripper of the feed hydrotreater. Generally contamination by water results from a poor operation of this equipment.

Detection: Since water contamination is a major concern for the operator, on line analyzer is provided for the recycle gas. Operating experience shows that the optimum water content in the recycle gas must be within a range of 15 to $25 \mathrm{ppm}$ (vol.). The associated chlorine level will then be between 1 to $2 \mathrm{ppm}$ vol. Above $50 \mathrm{ppm}$ vol. of water, the reactor inlet temperature must be lowered to reduce the chlorine elution from the catalyst. The following figures are generally accepted:

$>50 \mathrm{ppm}$ vol. of water Temperature $<480^{\circ} \mathrm{C}$

$>100 \mathrm{ppm}$ vol. of water Temperature $<460^{\circ} \mathrm{C}$

Below $10 \mathrm{ppm}$ of water in the recycle gas, the catalyst acidic function is enhanced. Water injection may be used: $1 \mathrm{ppm}$ wt in the feed results in an increment of 2 to $5 \mathrm{ppm}$ vol. in the recycle gas. Anyway this normally never happens for CCR Reformer as the freshly reduced catalyst contents a certain amount of water.

Remedies: In case of water upset,

$\square$ Decrease reactor inlet temperature as indicated above.

Restore operating conditions upstream of the unit to reduce water contamination.

Check amount of oxygenated compounds in the feed.

$\square$ Halogens (chlorine, fluorine): The maximum allowable amount in the unit feed is $0.5 \mathrm{ppm}$ wt for each of them.

Mechanism: The presence of chlorine in the feed modifies the acidic function of the catalyst and promote the hydrocracking reaction. Once chlorine is eliminated, the proper chlorine balance of the catalyst can be restored. The effect of fluorine is similar but it is more difficult to remove from the catalyst.

Effect of Chlorine, Fluorine Contamination: Hydrocracking reactions are enhanced:

- Lower reformate liquid product yield.

- Higher LPG and CL yields.

- Slightly higher octane.

- Decrease of hydrogen production. 
Prevention and Causes of Contamination: Chlorine and fluorine are sometimes present in crude as organic halides owing to the technical of the production field. They are normally eliminated in the pretreatment stage, but if present in notable quantity (several wt ppm) can lead to a huge corrosion in the cold part of the HDT reaction section.

\section{Permanent Poisons}

Permanent poisons have been defined as contaminants which irreversibly damage the catalyst.

Mechanism: Most metals poison the metal function (platinum and promoter) of the catalyst. Metal poisons tend to affect the first reactor, then to break through and affect the 2 nd reactor. The first reactor is typically the reactor where the poisoning is first detected. As in CCR reformer unit catalyst is circulating from 1 st reactor to the successive ones poisoning can affect the whole catalyst hold-up if the cause of pollution is not found.

Effect of Metal Contamination: Metal contamination is characterized by:

- A dramatic decrease of the $\Delta \mathrm{T}$ in the first reactor associated with an increased $\Delta \mathrm{T}$ in the second reactor.

- A decrease in octane number.

- An increase in liquid product yield.

- Decrease of hydrogen production.

In addition, mechanical problems may result from the collection of corrosion products (scale, rust...) in the first layer of the first catalyst bed, or the accumulation of scale, rust in the dead ends, of the first reactor.

Prevention and Causes of Contamination: The contaminants and the source of contamination are listed in Table 3 above. Prevention consists of adequate hydro treating and appropriate material selection to limit corrosion. Metal poisons are generally partially retained on the upstream hydro treating catalysts. However the retention capacity is limited and breakthrough may occur. Such a breakthrough would result in a very harmful situation for the unit since these poisons would not be eliminated by the catalyst regeneration.

It is very important to check periodically the metal content of the hydrotreater feed and product. It enables to monitor the performance of the hydrotreater with regard to demetallization and also to be warned of a possible metal breakthrough of the hydro treatment catalyst, providing the maximum metal retention of the hydro treatment catalyst is known.

Coke: The coke which deposits on the catalyst is a temporary poison since its detrimental effect is reversible through regeneration. Owing to its paramount importance in catalytic reformers, coke formation is treated separately.

Mechanism: Indene derivatives, poly nuclear aromatics, naphthenes are the assumed precursors of coke formation. They result either from slight amounts of polynuclear aromatics in the feed (depending upon the nature of the crude and the end point of the feed) or from the aromatics producing reactions of the reforming process itself. Some diolefin intermediates of reforming reactions are also potential coke precursors. Coke deposit affects the catalyst activity by reducing the contact area between catalyst and the reactants. The normal coke content of the catalyst lies between 4 to $6 \%$ by weight. "Normal" means through-put, feedstock quality and severity within the range defined in the relevant section of the process book, and catalyst circulation within the design operating range. Catalyst with noticeably higher coke content can be handled provided a few precautions are taken (Refer Adjustment of operating conditions). Somewhere below 3\% wt of coke, the operation of the regeneration may become unsteady and it is recommended to momentarily shut it down.

Prevention and Causes of Contamination: Since coke formation is inherently associated with the reforming reactions, there is no real way to avoid it. Coke will be reduced by a decrease of reactor temperature (i.e. if severity is reduced) and an increase in hydrogen circulation. Low total pressure, to the contrary, favors coke formation. Hence the need for a continuous regeneration for reforming units which operate at high severities (high temperature) and low pressure. Another parameter to watch, to minimize coke is the feed end point, in order to limit heavy poly aromatics amount. In European countries the maximum allowable feed end point must not exceed $180^{\circ} \mathrm{C}$ (ASTM D86), as the marketed gasoline end boiling point is limited at $205^{\circ} \mathrm{C}$. Note that in case of mixed feeds (use of imported naphtha, SR+ cracked naphtha, etc...) the final boiling point of the mixture does not give sufficient information. Each feed shall be analyzed separately as to know the final boiling point of each stream.

Catalyst distribution in reactors: Thermodynamics and kinetics have shown that there is an optimum operating temperature range, approximately $450^{\circ} \mathrm{C}$ $520^{\circ} \mathrm{C}$ in order to simultaneously favor the rate of the desirable reactions and limit the undesirable ones to an acceptable level. For each specific case, the most appropriate operating temperature is selected taking account of the feed quality (PNA, distillation range ...) and product requirement (octane). Owing to the great endotherm city of the most important and desirable reactions (naphthenes dehydrogenation and paraffin's Dehydrocyclization) this optimum temperature cannot 
be sustained through-out the whole catalyst volume. In addition, dehydrogenation is also, by far, the fastest reaction, which means that the temperature drops very sharply over the first part of the catalyst.

In order to restore the catalyst activity, when temperature has dropped to a certain level which depends upon the reactions involved, the reactor feed is reheated. To achieve this, the catalyst is distributed in several reactors ( 3 or 4 ) and intermediate heaters are provided.

\section{A Review of History and Studies}

After World War I, due to the expansion of industries and the growing demand for energy and petroleum products, oil refinement scientists gradually achieved to the great success with introducing molecular failure processes, increasing the quality and quantity of various oil products and products, and in this they achieved great success. Thermal cracking, also known as Shukhov cracking, was introduced in 1891 by the Russian engineer Vladimir Shukhov [13].

The process was then corrected by an American engineer William Burton in 1913. This process was soon taken into account in the oil refining industry as far as between 1920-1935 the rate of gasoline produced by thermal cracking doubled the amount of gasoline produced from the crude oil [14]. Over time, experts could produce better gasoline by cracking catalysts compared to thermal cracking. The catalytic cracking method was presented in 1923 by the French engineer Eugene Houdry and the first industrial unit was made in 1936 by the Houdry Company at the United State [15, 16]. Thus, by the year 1940, the gasoline octane number was either increased by the Houdry catalytic cracking process or by some of the more common octane additives such as iso octane or tetraethyl lead [15].

By the end of 1940, Dr. Vladimir Hansel, a Russian chemical engineering researcher at U.O.P Company, developed and presented for the first time the naphtha catalytic conversion process by using a catalyst containing platinum. But platinum was a very expensive metal found only in Russia and South Africa, so it was not economical to use the metal as a catalyst at an industrial scale.

After much research in 1947, Dr. Hansel proposed the use of platinum-metal particles on the alumina acid surface base to carry out chemical reactions to optimize and enhance the gasoline octane number. $\mathrm{He}$ showed that a catalyst, combining one hundred of a percent platinum on the surface of alumina, was able to maintain its activity and stability in the naphtha catalytic conversion process and octane number promotion. Due to his work on the catalyst level and the invention of various methods for optimizing the oil industry chemical processes, especially the valuable economic advances in relation to the hydrocarbons catalytic conversion process, he was honored with the award of the National Academy of Sciences of the United States in the field of chemistry department in 1981[16].

Subsequently, Dr. Hansel's process was developed by America U.O.P. Company in 1949 to produce high gasoline octane number from naphtha commerciallyscale, and this U.O.P Company process is known and called as plat forming process in the world. The first naphtha unit plat forming was built in 1949 at the old Dutch refinery in Michigan, USA, and the catalytic conversion reforming process was introduced in 1947 to 1949 functionally and industrially $[17,18]$.

Accordingly, this platform was developed and expanded seven years later, with the provision of 13 other commercial refining processes by other oil companies [19]. The completion and development of these processes continued in the next years, leading to the final design of this process, which is the naphtha catalytic conversion with movable bed catalyst for its continuous resuscitation. Subsequently, with the modification of the catalyst used in the catalytic conversion reforming process, its performance was more optimized. The most significant and effective correction occurred in the 1960s, the first reforming catalyst bimetallic (Platinum-Rhenium) was based on acidic alumina, resulting in a dramatic evolution in optimization of naphtha catalytic conversion process [20].

Since then, various models and methods of this kind of process have been developed and expanded by a number of large oil companies, and today, the vast majority of gasoline produced worldwide is derived from the catalytic conversion reforming process. The naming of naphtha catalytic conversion reforming processes to produce gasoline has been generally done and presented based on their technical know-how companies. The following is a list of the most famous brand names of gasoline reforming process in the world:

1- The Reforming process has been developed and presented by American Chevron Oil Company.

2. The Power forming process has been developed and presented by the Esso Oil Company.

3. The Houdry forming process has been provided by Houdry Process Company.

4. The plat forming process has been presented by American U.O.P. Company both for fixed bed type and continuous catalyst regeneration.

5. The Octanizing process has been developed and presented by French Axens Company, under the 
authority of the Institute France Petroleum (IFP) for reforming with continuous catalyst regeneration.

It should be noted that the technical expertise of gasification complex of refinery belongs to the French Axens company and, consequently, the reforming process is Octanizing, which has been studied in this study.

In 1959, Mr. Smith proposed the first kinetic model of naphtha catalytic conversion reactions. In this model, the reactants were divided into 10 false units. The primary components consisted of three main groups of paraffin's, naphthenes and aromatic compounds, and hydrogen and ethane and propane and butane were considered as separate components [21].

One year later, Mr. Krane presented another model that included the initial raw material consisting of 20 false elements and hydrocarbons 8 to 10 carbons in the form of 53 reactions.

In 1972, Mr. Kmak used the Langmuir kinetic model for the catalytic conversion process, and in 1983, Mr. Marin developed a model that contained 23 false elements and a hydrocarbon cutter of 5 to 10 carbons. These models were optimized by Mr. Froment in 1997, taking into account 35 false elements and 36 reactions.

Then Mr. Ostrovskii presented a mathematical model for gasoline catalytic conversion with a catalyst of KR-104A brand and using a hydrocarbon cutting of $62-150{ }^{\circ} \mathrm{C}$ from oil raw materials. Sharikov presented a model consisting of 12 false elements for calculating gasoline catalytic conversion in the radial and axial reactor substrates.

Finally, based on these models, Hyprotech companies and $\mathrm{KBC}$ introduced the Hysis Refinery software, which we are able to simulate the gasoline catalytic conversion unit. Later, KBC lonely provided a software that was called Petrosim.

In 2001, Kvartsov et al., by using software's and computer system calculations, taking into account the physical properties of the naphtha feed cuts in the catalyst conversion process for testing and selecting a suitable platinum catalyst and optimizing the conditions and preparing it for industrial application and predicting operating conditions associated with the catalyst regeneration cycle and increasing the unit operating efficiency based on process technology and the composition of hydrocarbons percentage in the refinery feedstock. Their method involves several evolutionary stages using statistical methods to create mathematical models based on the principles of chemistry physics, taking into account the quality of product and gender, and the catalyst type and composition of feed percent and in this research, the creation of a software platform for computer systems to enter and selecting the suitable catalyst type for naphtha conversion process. The majority of other studies presented in the field of naphtha catalytic conversion are not able to predict the actual and exact conditions and process parameters, since these process calculations of the industrial unit is widely dependent and effective on the inactivity of catalyst during the operation. In order to take this into account, it is necessary to consider the transition conditions in the models of kinetic equations of reactions.

Accordingly, one of the highlights of this research and model is that the catalyst activity is the main criterion according to the output and flow characteristics of the product, and the amount of process feed and catalyst output conditions, the effect of reducing the catalyst activity in the process for gasoline octane number with flow per ton per hour per 95 ton of naphtha feed [22].

In 2006, Mnushkina et al., attempted to optimize the naphtha catalytic conversion process with the aim of producing gasoline reformate with less than $1 \%$ weight benzene by mathematical modeling. The result of this study is the presentation of two new versions of the benzene separation method from the reaction mixture, the first one including the production of benzene reformate containing $0.01 \%$ weight of benzene, with a $12 \%$ reduction in catalytic conversion process yield, and the second edition of gasoline reformate containing $0.47 \%$ weight benzene and $2.9 \%$ increase in process yield. The proposed versions are in accordance with the standard requirements of Euro 2000 in the gasoline product field. The produced gasoline is a result of naphtha cuttings catalytic conversion which is usually contains 2 to 7 percent benzene and in the worst case, up to 70 percent of toxic substance is in benzene. In this study, we tried to dilute the high-octane reformate with the high-cost components of high octane and to use the conventional processes proposed to reduce the benzene rate in produced reformate and eco-friendly and clean gasoline production. The benzene reduction technology in reforming product is usually divided into two main groups:

The first group is based on the methods for separating materials in a unit feed that produce benzene in the process. The proposed research is separating the cut of 82-105 ${ }^{\circ} \mathrm{C}$ of naphtha feed, which results in an approximate reduction of benzene content in the product to $1 \%$. Most importantly, this method is carried out at low operating pressure, which is why this optimization method is not suitable for Russian refineries operating at high pressure. The second group is based on technologies that physically and chemically reduce the benzene rate in reforming product. Such as the benzene hydrogenation method 
by cyclohexane formation, which also results in a slight reduction of octane number, or benzene separation by extraction method or benzene alkylation with low molecular weight olefins or partial reformate component separation methods. It should be noted that the combination and integration of the above technologies and emergence of a more appropriate and new way is possible. In this research, a new process design for optimization was proposed by analyzing various reforming technologies. The basis of this scheme was the separation of benzene from the reaction mixture before entering the second reactor, which resulted in the benzene rate reduction in the final reformate product [21].

In the same year, HOU Weifeng et al. provided a model containing 18 new kinetic equations for naphtha catalytic conversion process reaction by using Aspen Plus software as a functional module for process simulating and developing and expanding this model and optimizing it. Functional techniques, robust databases, complete modules set, flexible systems of Aspen Plus software system, and maintenance of the proposed kinetic model specifications are all of the strengths of this research and the computational results are consistent with almost the practical industrial data. The results of this proposed model simulation to optimize a unit of naphtha catalytic conversion process for 2 months' experiment were compared with information and practical data. According to this paper authors, the experiment has shown that the benefits of implementing this optimized model has been increased by an average over 1,000 Yuan per hour for the process [22].

One year later, again, $\mathrm{Hu}$ Weifeng et al. by using a multi-purpose strategy, introduced a more complete network-based process model containing 20 chemical reaction kinetics equations to optimize the naphtha continuous catalytic conversion unit with the aim of achieving a high aromatics product for higher octane. The decision making variables were selected for four reactor temperature and reaction pressure and a hydrogen to naphtha ratio. To solve this problem, the multi-purpose optimization of the genealogy algorithm named NAJA has been used by the named authors. In order to find the relationship between the variables and the two objective functions and choice of the appropriate solution, the Pareto set method, which is the principles of optimization techniques, has used [23].

In 2010, Gyngazova et al., analyzed the mathematical modeling of the gasoline catalytic conversion with continuous restoration process. Their proposed model includes calculating the catalyst movement, catalyst activity changes due to the coke formation and deposition along the length of reactor bed and the relationship between catalyst activity and their circulation ratio. In this study, they calculated and solved the inverse kinetic problems, and determined the kinetic parameters of the catalyst under continuous operating conditions, and thus, they were able to calculate and predict the composition percentage of gasoline reformate product.

The results of this model were compared with experimental data and chromatographic analysis. The result of this comparison suggests that the model is consistent with experimental data. The mentioned model is applicable to the calculation of gasoline forecast for various naphtha raw materials combinations. The catalytic conversion model structure depends on the number of reactants and the reaction kinetics type model [26].

One year later, Majid Saeidi et al., also proceeded to model and simulate a catalytic conversion unit with continuous regeneration which in this model, reactions patterns and reactors were modeled based on mathematical rules and using mathematical software. This network-based process model consists of 12 kinetic equations of reaction that have been shown their effectiveness on industry-specific items [24]. The naphtha feed intended of the study consists of 25 sets of components, such as C6-C9 hydrocarbons, in three groups of paraffin's, naphthenes, and aromatics. In this research, after simulation for optimization, suitable and applicable constraints have been used for proposed kinetic model that has been effective in increasing process yield and unit benefit. The study modeling and simulation results have been consistent with the actual results of the industrial process of the catalytic conversion unit of continuous revival. In this research, using the results of Mr. Aitani research, the kinetic equations of the molecular reactions network used in the naphtha catalytic conversion have been extracted [27].

One of the most important issues in matching the simulation with reality in the catalytic conversion processes is the catalysts ineffectiveness and inactivation due to the penetration and formation of coke layer on them, therefore, with regard to the important role played by the catalysts inactivation in the conversion operation industrial catalyst, presentation and use of kinetic equations, the catalyst inactivation reaction in modeling has a special and significant important. Therefore, Saeidi et al. have defined and specified the catalyst inactivation factor with the symbol $\varnothing$ after reactor modeling by using mass and energy equilibrium and solving differential equations, to predict coke formation and its effect on catalyst activity and reactor yield in this research. The equations used to determine and calculate the catalyst inactivation factor and the amount of coke formation 
during the process are based on empirical findings and expressions and are based on analysis and experimental and practical data [28,9]. In this research, the reaction kinetic constant is also used and calculated from the Arrhenius equation. Finally, the parameters and estimated variables in solving the optimization problem are obtained from the minimization of the objective function. In this study, lumping techniques have been used to predict the kinetic reactions of catalytic conversion processes. So, the naphtha feed is divided into 9 groups including $\mathrm{C} 1, \mathrm{C} 2, \mathrm{C} 3, \mathrm{C} 4$, and $\mathrm{C} 5$, aromatics, naphthenes, paraffin's and hydrogen. The reason for using this technique is to reduce the parameters used. By using the values obtained from a large set of laboratory data, it is possible to estimate the parameters, and finally the objective function has been obtained to minimize and optimize the process based on the GA algorithm and the temperature and molar component and the carbon group's number. This simulation results were consistent with the actual data extracted from the catalytic conversion unit with the continuous restoration of the some Refineries [29,10].

In 2011, Gueddar et al., used artificial neural network ANN methodology to simulate and optimize the catalytic conversion unit with continuous regeneration based on a nonlinear reduction model [29]. In this study, they developed and expanded the non-linear reduction model of the refinery process by producing and using different input and output data from the refinery. In this model, the complex process of catalytic conversion unit with continuous reduction of CCR for data generation has been used then by distributing large rates of dependent interconnected data which their numerical values are available at the refinery based on the separation and aggregation method of the proposed reduction model to approximate the optimization process has been addressed. In the neural network method, the existing data is subdivided into smaller subclasses and expanded into neural network models from each subset (Isolation). Then these ANN models are combined to obtain the final neural network model to provide all of the original production data [30].

One year later, Jingazua et al., investigated the optimization of catalytic conversion unit with continuous regeneration CCR in order to find the best and most appropriate proportion of flow rate in the catalytic circulation between reactors and the recovery section. In addition to using experimental equations and theoretical calculations, to study the formation and concentration of coke layer on the catalyst surface, laboratory and industrial data are also required. The results for the industrial platinum and alumina-based tin catalyst shows that the coke formed on the catalyst surface during reforming operation is shapeless and irregular and its rate at the reactor output is between 4 and 6\%, which depends on naphtha feed percentage and control parameters of unit process. In this study, the samples specific surface area has been obtained for a new catalyst 152 $\mathrm{m} 2 / \mathrm{g}$ and for a catalyst after reduction, $140 \mathrm{~m} 2 / \mathrm{gr}$ and for reactor output catalyst, $118 \mathrm{~m} 2 / \mathrm{gr}$. The results of these researches and studies have been shown that the most optimum ratio of catalyst circulation rates in order to increase the CCR unit efficiency and yield and maintenance and keeping the coke concentration at the lowest possible level and the highest specific surface area level for the catalyst, should be maintained and controlled around 0.008 to $0.01 \mathrm{~m} 3$. Reducing catalyst activity plays a very important role in the efficiency and efficiency of the catalytic conversion process [31].

In 2013, David Iran shah et al. contributed to simulate and naphtha catalytic conversion process with a continuous revival. In this simulation, they did reactor mathematical modeling of this process in two axial and radial directions, taking into account the cross flow pattern. Their new reaction network model is based on 32 false elements and 84 kinetic equations of reaction. The obtained results from this model are compared with industrial data that is acceptable [32].

In 2013, Mohammadi et al. investigated hydrodynamic simulation and heat transfer of naphtha catalytic conversion reactors. In this paper, the mass survival equations, momentum, and energy along with turbulence equations simultaneous are solved in finite volume element systems. In these reactors, distribution of fluid residence time has been achieved by using an injection stair tracking technique of gate. The flow dispersion parameter has been located and reported in all three reactors. Acceptable structural corrections have been made in the system to achieve proper flow conditions and increase capacity. It was found that increasing the gate capacity and increasing the resistance of the current distributors will help to improve the flow uniformity. In order to consider the produced or consumed heat in the porous region containing a catalyst in which there is a lot of reactions, the source terminology of the spring or heat well is replaced by the energy equation. This study results have been shown that the major drop in temperature occurs at the first reactor. The thermal conditions of the system are investigated by replacing the insulation conditions of reactor shells. They showed that the use of insulation with a thickness of twice the current or insulation with a thermal conductivity of less than $0.06 \mathrm{w} / \mathrm{m}$. $\mathrm{k}$ is almost equivalent, which in turn reduces the system thermal dissipation. 
Finally, according to studies and various simulations with different boundary profiles, it was found that system thermal dissipation can be reduced around $40 \%$ from the current value, which results in an increase in output product octane number. The RSM turbulence model has shown a better thermal volume mixing than other turbulence models. The maximum rate of relative error percentage compared to the experimental data for predicting the temperature in the whole system is less than $6 \%$, which indicates the high accuracy and validity of the calculations and simulation [31-34].

In 2019, Samimi et al wrote one article about "Use of Data Mining in the Corrosion Classification of Pipelines in Catalytic Reforming Units (CRU)". They told that: computational tools for analyzing and collecting data in the operation of petroleum units are essential. One of the methods is the classification or regression is to step in the overall process of knowledge extraction. In this study, one of specific type of decision called the conditional contract arrangement, is used to extract the relevant knowledge in Catalytic Reforming Units (CRU) for 4 factors: Density, $\mathrm{PH}$, total iron ions in vessels (S.FE) and $\mathrm{H}_{2} \mathrm{~S}$. All of these factors are related to corrosion in CRU and this paper aims to optimize some conditions to eliminate it. In this regard, using ammonium water with a specific range and $\mathrm{PH}$ can be helpful. According to the obtained results the best range of density (in Feed) is less than $0.515 \mathrm{~kg} / \mathrm{m} 3, \mathrm{PH}$ (water in vessels) is more than 6.7, S.FE is less than $1.5 \mathrm{ppm}$ and $\mathrm{H}_{2} \mathrm{~S}$ in recycle gas is less than $700 \mathrm{ppm}$. The outcomes also show how this approach can be used to gain insight into some refineries and how to deliver results in a comprehensible and user-friendly way.

\section{Conclusion}

One of the most important properties and quality features of a high quality gasoline product is low level of pollutants such as sulfur, benzene, and aromatic compounds such as sulfur, benzene, and aromatic compounds and lead and manganese particles from environmental standards, octane number of the fuel. The higher the octane number is, the fuel is more resistant to combustion, pressure and heat. Basically, the octane number is a measure to indicate the gasoline resistance to the heat, push and start of spontaneous combustion. The octane number is a fully conventional quantity of terms that have assumed the normal octane number of heptane, zero and the isooctane 95, and the rest of the compounds have been calculated to these two. Regarding the mentioned cases, it is obvious that the conversion of normal paraffin hydrocarbons to iso paraffin's, naphthenes and aromatics leads to an increase in the octane number. The importance of the gasoline octane number parameter is that one way to increase the engine power and output is to increase their concentration ratio, but this is achieved only by increasing the strength of the gasoline resistance to spontaneous combustion, which is the same concept of the octane number.

Another important characteristic of gasoline is the amount of benzene present in it. The maximum allowable limits of benzene conform to the 2005 European standard in gasoline is 1 volume percent. In the United States, however, it has been announced recently that the amount of benzene in the country would be reduced to $0.62 \%$ by 2015 [37]. Therefore, in optimization of gasoline product, effective parameters on benzene reduction are also considered.

Naphtha's catalytic conversion unit is a continuous revival with the commercial name Octanizer of refinery with a capacity of $30,000 \mathrm{~b} /$ day with the aim of increasing the octane number of the refined heavy naphtha flow to 95 .

However, reaching the conditions and specifications of the product due to forced changes in unit capacity, composition of food and fluctuations of control variables and different operational conditions need to know practical solutions and meet the optimal values of each process parameters related to each specific operational conditions. The fundamental reforming reactions can be split into two parts:

(i) Positive reactions i.e. reactions which lead to an aromatic content increase, these are the reactions you wish to promote.

(ii) Negative reactions i.e. reactions which not only lead to an octane decrease but to a loss of reformate yield. These reactions are obviously the ones you wish to avoid.

One of the most important process in refineries is Naphtha catalytic conversion. In this process, gasoline with high octane number produce in the petrochemical complexes of precious aromatics such as benzene, toluene and xylene. Due to the importance of fuel and its more production of initial oil materials and the optimization possibility and catalytic reactor performance improvement in order to increasing the quality and quantity of products, the necessity of simulation and investigation the involved parameters and its performance improvement will be necessary. This process contains three numbers radial flow reactors, furnace, a separator tank, some thermal conversion and a compressor which has been done more than 300 .

\section{Acknowledgement}

The work presented in this paper is part of a research project of Amir Samimi (Ph.D. student in science in chemical engineering, Department of Chemical 
Engineering, Mahshahr Branch, Islamic Azad University, Mahshahr, Iran).

\section{References}

[1] Samimi, A., Zarinabadi, S., Kotanaei, S., Hossein, A., Azimi, A., \& Mirzaei, M. (2019). Use of data mining in the corrosion classification of pipelines in catalytic reforming units (CRU). Iranian Chemical Communication, 681-691.

[2] Stanley, G. (2006). A Biographical Memoir of Veladimir Haensel, 3rd ed., The National Academy of Sciences, Washington DC, Vol. 88

[3] Samimi. A. Zarinabadi. S. Shahbazi. A. Azimi. A. Mirzaei. M. (2020). Journal of Medicinal and Chemical Sciences, 3, 79-94.

[4] Moghadasi, Z. (2019). Journal of Medicinal and Chemical Sciences, 2(1), 35-37.

[5] Cho, W., Song, T., Mitsos, A., McKinnon, J. T., Ko, G. H., Tolsma, J. E., ... \& Park, T. (2009). Optimal design and operation of a natural gas tri-reforming reactor for DME synthesis. Catalysis Today, 139(4), 261267.

[6] Sajjadifar, S., Pal, K., Jabbari, H., Pouralimardan, O., Divsar, F., Mohammadi-Aghdam, S., ... \& Hamidi, H. (2019). Characterization of Catalyst: Comparison of BrØnsted and Lewis Acidic Power in Boron Sulfonic Acid as a Heterogeneous Catalyst in Green Synthesis of Quinoxaline Derivatives. Chemical Methodologies, 3(2. pp. 145-275), 226-236.

[7] Bobtana, F., Elabbar, F., \& Bader, N. Evaluation of Halocnemum Strobilaceum and Hammada Scoparia Plants Performance for Contaminated Soil Phytoremediation. (2019). Journal of Medicinal and Chemical Sciences, 2(4), 126-129.

[8] Alkherraz, A. M. Ali, A. Elsherif, K. K. M. (2020), Journal of Medicinal and Chemical Sciences, 3(1), 1-10

[9] Nirmala, G. S., \& Muruganandam, L. (2019). Hydrodynamics in a Liquid Solid Circulating Fluidized Bed-A Review. Journal of Chemical Reviews, 1 (2. pp. 78-170), 114-129.

[10] MArsAro, M. F., \& CAVAlCAnte, C. A. V. (2017). Random preventive maintenance policy based on inspection for a multicomponent system using simulation. Eksploatacja

Niezawodność, 19(4).

[11] Amini, I., Pal, K., Esmaeilpoor, S., \& Abdelkarim, A. (2018). Prediction of two- dimensional gas chromatography time-offlight mass spectrometry retention times of 160 pesticides and 25 environmental organic pollutants in grape by multivariate chemometrics methods. Advanced Journal of Chemistry-Section A, 1(1, pp. 1-65), 1231.

[12] Aurelien, M. D. DouetteScott, Q. Turn Wuyin WangVheissu I. Keffer, (2007)"Experimental Investigation of Hydrogen Production from Glycerin Reforming,"Energy Fuels, 21(63), 4993504.

[13] Taskar, U., \& Riggs, J. B. (1997). Modeling and optimization of a semiregenerative catalytic naphtha reformer. AIChE Journal, 43(3), 740-753.

[14] Mohamed Abd., El-Kodous Mohamed., Abd El-Kodous., Gharieb Gharieb., El-Sayyad., Gharieb El-Sayyad., Ahmed el-batal., Ahmed el-batal., (2019). Preparation and characterization of new recyclable visiblelight responsive nanocomposite for photocatalysis applications, Journal of Materials Science Materials in Electronics, 30(3), 1-17.

[15] Liao, Z., Wang, J., Yang, Y., \& Rong, G. (2010). Integrating purifiers in refinery hydrogen networks: a retrofit case study. Journal of Cleaner Production, 18(3), 233-241.

[16] Sa'idi, M., Mostoufi, N., \& SotudehGharebagh, R. (2011). Modeling and simulation of continuous catalytic regeneration $(\mathrm{CCR})$ process. International Journal of Applied Engineering Research, 2(1), 115 ..

[17] Liang, K. M., Guo, H. Y., \& Pan, S. W. (2005). A study on naphtha catalytic reforming reactor simulation and analysis. Journal of Zhejiang University. Science. B, 6(6), 590.

[18] Ciapetta, F.G., Wallace, D.N., (1971), Catalytic Naphtha Reforming, Marcel Dekker Inc., Maryland, Vol. 5, p. 61-158.

[19] Smith, R. B. (1959). Kinetic analysis of naphtha reforming with platinum catalyst. Chem. Eng. Prog, 55(6), 76-80.

[20] Gyngazova, M. S., Kravtsov, A. V., Ivanchina, E. D., Korolenko, M. V., \& Uvarkina, D. D. (2010). Kinetic model of the catalytic reforming of gasolines in moving-bed reactors. Catalysis in industry, 2(4), 374-380.

[21] Kvartsov, A. V., Ivanchina, E. D., D'yakonova, L. V., \& Averin, S. N. (2001). 
Computer prediction of catalytic reforming of naphtha cuts. Chemistry and technology of fuels and oils, 37(6), 393-400.

[22] Mnushkina, O. I., Kas'yanov, A. A., \& Samoilov, N. A. (2006). Optimization of the reforming process scheme. Chemistry and technology of fuels and oils, 42(3), 176-182.

[23] Weifeng, H., Hongye, S., Yongyou, H., \& Jian, C. H. U. (2006). Modeling, simulation and optimization of a whole industrial catalytic naphtha reforming process on Aspen Plus platform. Chinese Journal of Chemical Engineering, 14(5), 584-591.

[24] HOU Weifeng, SU Hongye, MU Shengjing, CHU Jian, 2007, Multi objective optimization of the industrial naphtha catalytic reforming process, Chinese Journal of Chemical Engineering, Vol. 15, Issue 1, p. $75-80$.

[25] Ancheyta-Juárez, J., \& Villafuerte-Macías, E. (2000). Kinetic modeling of naphtha catalytic reforming reactions. Energy \& Fuels, 14(5), 1032-1037.

[26] Antos, G. J., Aitani, A. M., \& Parera, J. M. (1995). Catalytic naphtha reforming: science and technology. Marcel Dekker Inc.

[27] Raseev, S. (2003). Thermal and catalytic processes in petroleum refining. CRC Press.

[28] Marin, G. B., \& Froment, G. F. (1989). The development and use of rate equations for catalytic refinery processes. In Studies in Surface Science and Catalysis (Vol. 53, pp. 497-511). Elsevier.

[29] Gueddar, T., \& Dua, V. (2011). Disaggregation-aggregation based model reduction for refinery-wide optimization. Computers \& chemical engineering, 35(9), 1838-1856.

[30] Gyngazova, M. S., Chekantsev, N. V., Korolenko, M. V., Ivanchina, E. D., \& Kravtsov, A. V. (2012). Optimizing the catalyst circulation ratio in a reformer with a moving bed via a combination of real and computational experiments. Catalysis in Industry, 4(4), 284-291.

[31] Iranshahi, D., Karimi, M., Amiri, S., Jafari, M., Rafiei, R., \& Rahimpour, M. R. (2014). Modeling of naphtha reforming unit applying detailed description of kinetic in continuous catalytic regeneration process. Chemical Engineering Research and Design, 92(9), 1704-1727.

[32] Stijepovic, M. Z., Vojvodic-Ostojic, A., Milenkovic, I., \& Linke, P. (2009). Development of a kinetic model for catalytic reforming of naphtha and parameter estimation using industrial plant data. Energy \& Fuels, 23(2), 979-983.

[33] Arani, H. M., Shirvani, M., Safdarian, K., \& Dorostkar, E. (2009). Lumping procedure for a kinetic model of catalytic naphtha reforming. Brazilian Journal of Chemical Engineering, 26(4), 723-732.

[34] Palmer, E. R., Kao, S. H., Ung, C., \& Shipman, D. R. (2008). Consider options to lower benzene levels in gasoline. Hydrocarbon Processing, 87(6), 55-55.
How to cite this manuscript: Amir Samimi, Soroush Zarinabadi, Amir Hossein Shahbazi Kootenaei, Alireza Azimi, Masoumeh Mirzaei, Study of Operational Conditions in Octanizer and Hydro-Treating Units in Oil Refinery Company, Journal of Chemical Reviews, 2019, 1(3), 164182. 